\title{
Impact of sea breeze on vertical structure of aerosol optical properties in Dunkerque, France
}

\author{
Neda Boyouk ${ }^{\mathrm{a}, 1}$, Jean-François Léon ${ }^{\mathrm{b}, *}$, Hervé Delbarre $^{\mathrm{c}}$, Patrick Augustin ${ }^{\mathrm{c}}$, Marc Fourmentin ${ }^{\mathrm{c}}$ \\ a Laboratoire d'Optique Atmosphérique, CNRS-Université Lille 1, Villeneuve d'Ascq, France \\ ${ }^{\mathrm{b}}$ Laboratoire d'Aérologie, CNRS-Université Paul Sabatier, Toulouse, France \\ ${ }^{c}$ Laboratoire de Physique et Chimie de l'Atmosphère, CNRS-Université du Littoral Côte d'Opale, Dunkerque, France
}

\begin{abstract}
During July 2008, we used an elastic backscattering LIDAR to monitor the aerosol vertical distribution at the coastal area of Dunkerque, France. Here we report the sea breeze event which was observed with more highlighted effect of aerosol on 25 July. By combining LIDAR measurements with Sun photometer-retrieved aerosol optical thickness, we estimated an average LIDAR ratio of $33 \mathrm{sr}( \pm 14 \mathrm{sr}$ ) for the estimation of aerosol extinction profiles during the sea breeze. The LIDAR derived aerosol extinction in the first $200 \mathrm{~m}$ is clearly affected by the sea breeze and increases by more than $100 \%$ at the time of sea breeze arrival. A sharp convective boundary layer height decrease is observed in the LIDAR data due to the formation of the thermal internal boundary layer in the lowest part of the sea-to-land flow. PM2.5 concentration increases due to the thermal internal boundary layer formation and reaches its maximum between 1 and $2 \mathrm{~h}$ after the front overpass. Except during the front overpass, the PM2.5 is well correlated to the inverse of the mixing height detected by the LIDAR.
\end{abstract}

\section{Introduction}

The sea breeze is a well-known meso-scale meteorological phenomenon (Miller et al., 2003; Simpson, 1994) that is primarily attributed to the horizontal temperature gradient between land and water in coastal zones. The sea-breeze system has been extensively studied and modelled in numerous previous studies(Miller et al., 2003; Steyn and Oke, 1982; Chen and Oke, 1994) devoted to dynamical concerns. Cool and stable marine air encounters a thermodynamically unstable situation when it advects over a hot land surface. As the marine air mass moves inland and conducts heat from the land surface, a convective current begins to develop, and modified air is transported vertically. The vertical mixing results in a thermal

\footnotetext{
* Corresponding author.

E-mail address: jean-francois.leon@aero.obs-mip.fr (J.-F. Léon).

1 Now at Laboratoire de Météorologie Dynamique, CNRS-Institut Pierre Simon Laplace, Palaiseau, France.
}

internal boundary layer (TIBL) near the Earth's surface whose upper limit increases nonlinearly with distance from the coast (Miller et al., 2003; Levitin and Kambezidis, 1997).

Sea breezes impact on air quality of coastal areas under different mechanisms (Abbs and Physick, 1992; Kitada, 1987; Simpson, 1994). Above the TIBL the remaining unmodified marine air acts as a cap that prevents mixing between destabilized marine air below and the advected air above (Miller et al., 2003; Stull, 1988). The locally emitted pollutants are then trapped in this shallow TIBL resulting in an increase in their surface concentration. The impact of sea breezes on air quality is of particular interest in trade harbors and their vicinities, which are often concerned with poor air quality downwind from sources (Georgieva et al., 2007). The role of the sea breeze phenomenon on pollution has also been tackled in several campaigns devoted to photochemistry and ozone pollution in big cities like Marseille (Cros et al., 2004; Drobinski et al., 2007; Delbarre et al., 2005; Augustin et al., 2006; Mestayer et al., 2005) or Athens (Melas et al., 1995; Ziomas, 1998; Melas et al., 1998). 
The harbor of Dunkerque, France is one of the largest trade harbors in Europe and locally contributes to major emissions of pollutants such as $\mathrm{NO}_{x}, \mathrm{SO}_{2}, \mathrm{CO}, \mathrm{CO}_{2}, \mathrm{VOC}$ and aerosols (Rimetz-Planchon et al., 2008). Dunkerque district experiences sea breezes from May to September (Damato et al., 2003). Their occurrence depends on the thermal gradient between land and sea but also on large scale weather systems, and is favored by the presence of the North European anticyclone (Damato et al., 2003). Sea breeze days in Dunkerque's area are in majority associated with poor air quality. (Rimetz-Planchon et al., 2008) report that $46 \%$ of high polluted days were influenced by sea breezes during the warm period of 2002 .

The vertical stratification of the atmosphere during sea breeze events is of crucial importance in understanding the impact of sea breeze circulation on ground-level air pollution (Oke, 1978). Elastic backscatter LIDAR provides an interesting insight into the structure of sea breeze (Kolev et al., 1998; Nakane and Sasano, 1986; Murayama et al., 1999; Sicard et al., 2006). From a technical point of view, Rayleigh-Mie LIDAR are becoming widely used instruments and it is of interest to understand how optical remote sensing could be extrapolated to aerosol-mass measurements, within each specific meteorological event. The vertical variability in the return signal provides information on the stratification of aerosol layers. The sea breeze vertical structure in the Dunkerque area has already been investigated by (Talbot et al., 2007). During a 4-day field experiment in September 2003, they performed LIDAR observation of sea breezes using a UV differential absorption system (see (Kölsch et al., 1992), for a description of the UV LIDAR system). With a combination of sodar soundings and meso-scale numerical modeling, they identified the different components of the sea-breeze circulation including the front, headwind, gravity current and TIBL.

In this paper, we report LIDAR observations acquired during a field campaign in July 2008 in Dunkerque. The recent development of compact eye-safe LIDAR fosters a systematic use of LIDAR for unattended operation for long-term monitoring (Léon et al., 2009). This paper deals with the role of sea breeze on the aerosols dispersion in a specific case of an industrial and urban area at microscale (about $10 \mathrm{~km}$ or below) around industrial sources. We have used a compact commercial eye-safe elastic backscattering LIDAR for continuous monitoring of aerosol vertical distribution during a 10-day operating period. The analysis is focused on the detection of the aerosol vertical stratification occurring during sea breeze and the impact of this stratification on ground-level PM concentrations.

\section{Instrumentation and method}

We have used a Rayleigh-Mie backscatter LIDAR manufactured by Leosphere (Lolli et al., 2008). The LIDAR uses a tripled, pulsed Nd:YAG laser source at $355 \mathrm{~nm}$ with an output energy of $16 \mathrm{~mJ}$ and pulse repetition rate of $20 \mathrm{~Hz}$. The correcting overlap factor for short-range heights where the field of view of the telescope does not overlap the laser beam is close to 1 at $200 \mathrm{~m}$ above the telescope. To increase vertical resolution and access altitude below $200 \mathrm{~m}$, the LIDAR was tilted by a zenith angle of 50 degrees to the North (seaward). The observation ranges from $135 \mathrm{~m}$ above the LIDAR to about $10 \mathrm{~km}$ and the vertical resolution is $9.6 \mathrm{~m}$ (the projection of the raw range resolution, $15 \mathrm{~m}$, on the vertical axis). The LIDAR operated at the third floor of a building at the height of about $10 \mathrm{~m}$ above the ground and located at $2.368^{\circ} \mathrm{E}$ and $51.04^{\circ} \mathrm{N}$. So the first accessible altitude is located at $145 \mathrm{~m}$ amsl. The building is located between the urban and industrial area of Dunkerque and less than $1 \mathrm{~km}$ from the sea shore (Rimetz-Planchon et al., 2008, p. 7276 for a detailed map of the experimental are). The coastline is oriented EastWest so the sea breeze is southward.

The measurement period is from July 19 to 30,2008 . The LIDAR was working continuously with a time step of $4 \mathrm{~min}$, corresponding to average profiles over 4800 shots. The signal in the upper clear air is normalized on the molecular contribution (Russel et al., 1979; Chazette, 2003). The signal is corrected from the background sky radiance, which is acquired after each LIDAR profile. The aerosol extinction coefficient is derived for every 4-min LIDAR profile. However the mean and standard deviation extinction profiles are computed every $15 \mathrm{~min}$ (mean of 4 profiles except the first one using 3 profiles) to match the meteorological data timebase.

LIDAR data have been inverted using a well known method, based on Bernoulli's differential form of the propagation equation (Fernald, 1984; Klett, 1981). The backscatter LIDAR equation is undetermined due to its dependence on the two unknown backscatter and extinction coefficients (Ansmann and Müller, 2005). In the case of a single wavelength elastic backscatter LIDAR, it is necessary to consider an additional constraint for determining the LIDAR ratio (i.e., ratio of aerosol extinction-to-backscatter). This additional constraint is provided by simultaneous aerosol optical thickness (AOT) measurements acquired by an automatic Sun photometer (Holben et al., 2001) located on the same building as the LIDAR. The observed diurnal variability in the effective LIDAR ratio is further discussed in Section 4.

The mixing layer height is detected by analysing the temporal fluctuations in the LIDAR extinction profiles. This method has been extensively used (Hooper and Eloranta, 1986; Piironen and Eloranta, 1995) for the monitoring of the diurnal evolution of the convective boundary layer (CBL). Indeed, the turbulent mixing in the entrainment zone between tropospheric and boundary layer air results in a large variation in the LIDAR signal and consequently in the aerosol extinction coefficient. The maximum of the standard deviation extinction profile indicates the top of the mixing layer although the retrieved altitude is not exactly the mean height due to the effect of humidity on particles (Menut et al., 1999). In the case of weak mixing or stratification within the atmospheric boundary layer, several maxima in the standard deviation extinction profiles can be detected and thus unattended real time detection of the convective boundary layer top may fail with this method (Menut et al., 1999). We expect to also have a sharp variability in the LIDAR derived extinction profiles during the development of the TIBL due to convective mixing as the marine air is advected over land.

PM2.5 and PM10 (corresponding to the mass concentration of particulate matter with an aerodynamic diameter less than 2.5 and $10 \mu \mathrm{m}$, respectively) are measured using a Tapered Element Oscillating Microbalance (Patashnick and Rupprecht, 1991) operated by the air quality monitoring network of region Nord-Pas de Calais (ATMO Nord-Pas de Calais). Mass 
concentrations are recorded every $15 \mathrm{~min}$. We have chosen Dunkerque center station as it is the closest station $(600 \mathrm{~m}$ on the East) to the LIDAR. Wind direction and intensity, relative humidity and air temperature are recorded every 15 min close to the LIDAR position.

\section{Detection of sea breeze events}

Sea breezes are primarily driven by solar heating and sea breeze start depends on sunrise time (Simpson, 1994; Miller et al., 2003). Some of the following criteria identify the sea breeze days: warm season, high pressure, rapid change in the wind direction some hours after sunrise toward winds from the North sector, low initial wind speed before the change on wind direction, wind speed increase, northerly wind lasting several hours, no night wind blowing from the North sector, temperature drop of several degrees and increase in relative humidity. However, the synoptic wind is also a crucial factor on sea-breeze triggering as it can move the thermal gradient between land and sea. The observations discussed here were mainly made on clear days accompanying high pressure systems. During the observation period, we have observed four days with occurrence of sea breeze, on July 23, 24, 25, and 27 . On July 23 a high pressure system (1026 mbar) was located on the North of France and moved northward to Sweden on July 24 and 25 . Fig. 1a presents the daily variation of temperature, dew point and relative humidity on July 25 , the day of the most noticeable sea breeze. Fig. 1b gives the respective wind intensity, direction and also the meridional wind. Because the coastline is East-West, we plot the meridional wind to both highlight the increase in the wind speed and the northward rotation. Time is given in UTC which corresponds to local time minus $2 \mathrm{~h}$. Between 11:15 UTC and $12: 15$ UTC, the relative humidity increases from $40 \%$ to $70 \%$ and the temperature drops from $27.6^{\circ} \mathrm{C}$ to $21.6^{\circ} \mathrm{C}$ and the dew point temperature increases from 12.7 to $15.9^{\circ} \mathrm{C}$. The wind veered clockwise from South to North with an increase in the intensity from $3.1 \mathrm{~m} / \mathrm{s}$ to $5.4 \mathrm{~m} / \mathrm{s}$. This is clearly depicted in the meridional wind which shows an increase from $-2.2 \mathrm{~m} / \mathrm{s}$ to $5.4 \mathrm{~m} / \mathrm{s}$.

The arrival of the sea breeze front is always characterized by a rapid change in the 15-min mean meteorological parameters and PM concentrations. In Table 1, we have reported the change in meteorological parameters and PM concentrations observed over the frontal transition period when the air temperature is continuously decreasing (e.g. from 11:15 to $12: 15$ on July 25 , see Fig. 1).

An increase in PM10 and PM2.5 is simultaneously observed during the passage of the sea breeze front. The observed increase in PM10 is between 23 and $100 \mu \mathrm{g} / \mathrm{m}^{3}$ while it is between 5 and $15 \mu \mathrm{g} / \mathrm{m}^{3}$ for PM2.5 (Table 1). The increase in PM concentration during sea breeze events might be due to different factors (Rimetz-Planchon et al., 2008). The TIBL formation changes the mixing height of aerosols and consequently increases the PM concentrations at the ground-level. Moreover, the advection of marine air brings sea-salt aerosol over land. Lastly the gas-particle conversion rate factor might be enhanced because of lower temperature and increase in relative humidity and gas concentration.

Fig. 2 shows the variation of PM10 and PM2.5 as well as the ratio between PM2.5 and PM10 during the sea breeze
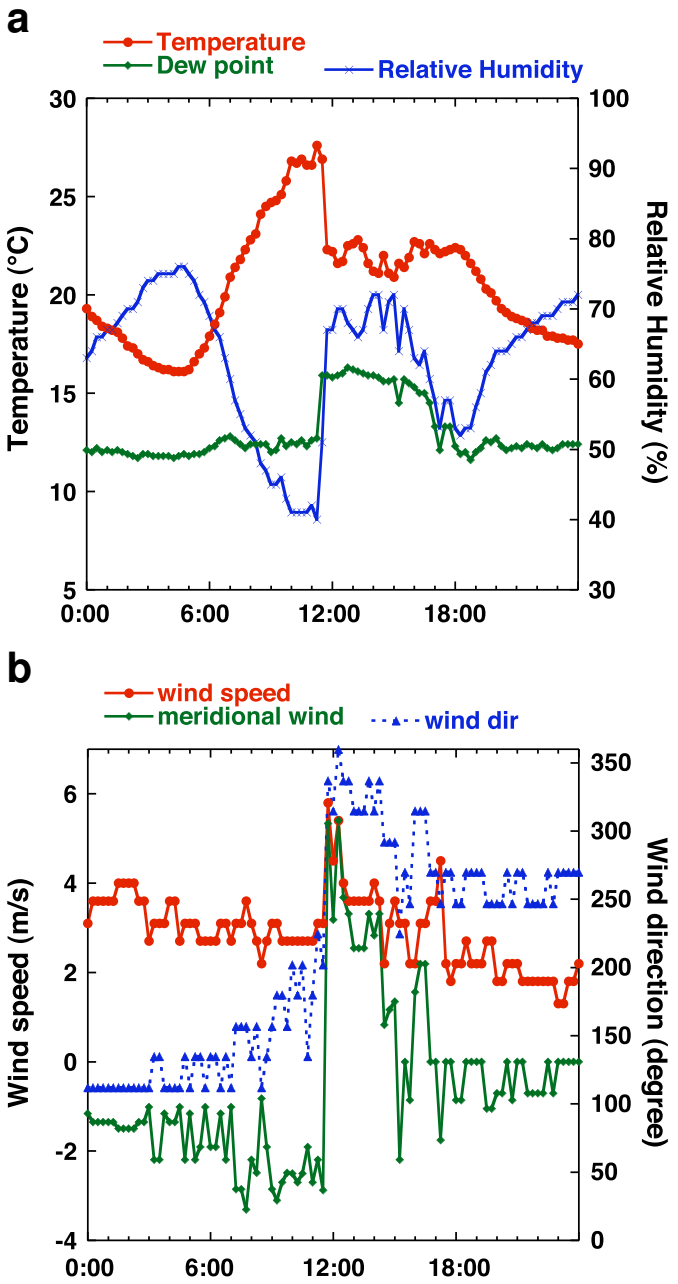

Fig. 1. Diurnal variation in (a) temperature, dew point and relative humidity and (b) wind intensity, meridional wind intensity and wind direction on July 25, 2008.

observed on July 25. After 7:00 UTC, the PM2.5 and PM10 concentrations decrease because of the development of the CBL. As the sea breeze starts, we observe a simultaneous increase in the PM10. A sharp increase of $97 \mu \mathrm{g} / \mathrm{m}^{3}$ from 27 to $124 \mu \mathrm{g} / \mathrm{m}^{3}$ is observed at the same time as the sea breeze front, i.e. between 11:30 and 11:45 UTC. Then the PM10 concentration fluctuates between a minimum of $80 \mu \mathrm{g} / \mathrm{m}^{3}$ and a maximum of $164164 \mu \mathrm{g} / \mathrm{m}^{3}$ that is observed at 13:45 UTC. The fluctuations in PM10 are closely associated with the variation in the meteorological parameters (Fig. 1). PM10 decreases back to its pre-breeze concentration after 18:00 UTC, at $28 \mu \mathrm{g} / \mathrm{m}^{3}$. The increase in PM10 on July 25 is equal to $359 \%$ and is the highest one observed during the experimental period. On July 23 and 24 , the observed increase is $152 \%$ and $185 \%$ respectively. On July 27 , the increase is also simultaneous with the sea breeze front overpass but much weaker than on July 25 . PM2.5 increases continuously during sea breeze (Fig. 2) to reach a maximum between 1.0 and $1.5 \mathrm{~h}$ after that the breeze starts. The sharp increase in PM10 is not observed in PM2.5. The ratio of PM2.5 to PM10 (Fig. 2) is 
Table 1

Variation in temperature $(\Delta T)$, dew point temperature $\left(\Delta T^{d}\right)$, wind intensity $(\Delta U)$, meridional wind intensity $(\Delta u)$, PM10 $(\Delta \mathrm{PM} 10)$ and PM2.5 $(\Delta \mathrm{PM} 2.5)$ during the given period of time on July 23, 24, 25 and 27, 2008. The onset time of the seabreeze is also given for each day.

\begin{tabular}{|c|c|c|c|c|c|c|c|c|}
\hline Date & $\begin{array}{l}\text { Onset time } \\
\text { UTC }\end{array}$ & $\begin{array}{l}\text { Time period } \\
\text { UTC }\end{array}$ & $\begin{array}{l}\Delta T \\
\left({ }^{\circ} \mathrm{C}\right)\end{array}$ & $\begin{array}{l}\Delta T^{d} \\
?\left({ }^{\circ} \mathrm{C}\right)\end{array}$ & $\begin{array}{l}\Delta U \\
(\mathrm{~m} / \mathrm{s})\end{array}$ & $\begin{array}{l}\Delta u \\
(\mathrm{~m} / \mathrm{s})\end{array}$ & $\begin{array}{l}\Delta \mathrm{PM} 10 \\
\mu \mathrm{g} / \mathrm{m}^{3}\end{array}$ & $\begin{array}{l}\Delta \mathrm{PM} 2.5 \\
\mu \mathrm{g} / \mathrm{m}^{3}\end{array}$ \\
\hline 23 July & $10: 15$ & $09: 45-10: 30$ & -3.9 & 1.8 & 4.5 & 3.7 & 41 & 5 \\
\hline 24 July & $13: 30$ & $13: 00-13: 45$ & -2.7 & 4.7 & 2.7 & 5.2 & 23 & 5 \\
\hline 25 July & $11: 45$ & $11: 15-12: 15$ & -6.0 & 3.2 & 2.3 & 7.6 & 100 & 15 \\
\hline 27 July & 09:30 & 09:15-10:45 & -4.0 & 0.9 & 1.3 & 4.1 & 32 & 12 \\
\hline
\end{tabular}

about $70 \%$ before the start of morning convection. The smooth decrease of this ratio toward 30\%-40\% may indicate that large particles are incorporated within the CBL. During the sea breeze front, the PM2.5/PM10 ratio drops to below $20 \%$ but is rapidly stabilized around 30\% until 18:00 when it goes back to $70 \%$. This diurnal cycle is coherent with the advection of sea salt landward during the development of the CBL and by the sea breeze flow.

The change in the vertical structure of the atmosphere due to the sea breeze is depicted by the 2-D plots of the logarithm of the range-corrected LIDAR signal (Fig. 3). In the morning, high values in the $2 \mathrm{D}$ plot corresponds to the mixing layer, which grows until 11:45 UTC. The sea breeze front is characterized by a sharp peak in the backscatter signal in the lowest part of the 2D plot after 11:45 UTC. The related increase of the attenuation causes a strong decrease in the observed signal.

\section{Impact on aerosol extinction vertical profiles}

The AOT is acquired during daytime for cloud-free conditions with an uncertainty of 0.02 (Holben et al., 2001; Estellés et al., 2006). We have quasi-continuous AOT observations during daytime only for July 24 ( 23 data points) and 26 measurements on July 21, 22, 28 and 30. Fig. 4 presents the Sun photometer AOT measurements acquired on July 24 . We can observe a slight increase in the AOT during the sea breeze, but there is no clear evidence of a direct impact, mainly because of missing data points. The AOT is interpolated according to the Ansgtröm law

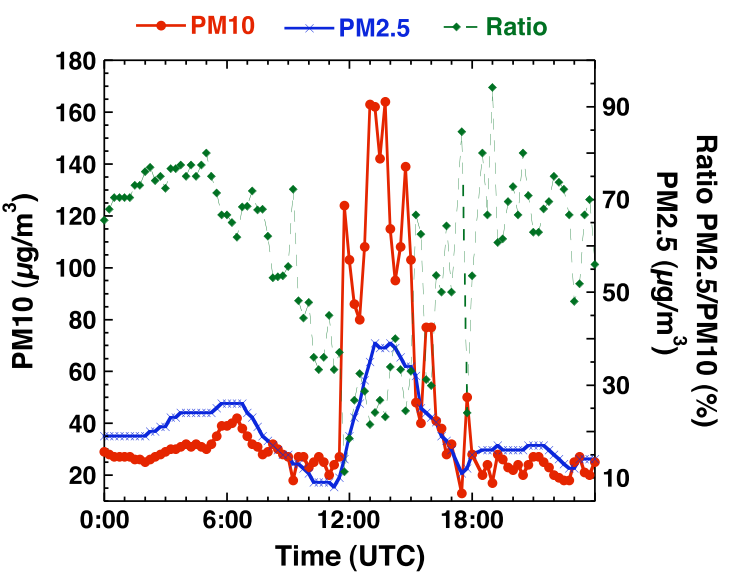

Fig. 2. 15-min average of PM10, PM2.5 and PM2.5/PM10 ratio recorded at Dunkerque Centre station on July 25, 2008.
(Angström, 1964) at $355 \mathrm{~nm}$ from measurements at 340 and $380 \mathrm{~nm}$. The Sun photometer AOT ranges between 0.15 and 0.79 for the whole data set. The calculation of aerosol extinction takes the angle of the LIDAR beam into account. There is no information on the possible vertical variability in the LIDAR ratio so it is assumed to be constant as a function of the range and consequently it should be considered as an effective LIDAR ratio. The vertical integration of the LIDAR derived aerosol extinction coefficient matches the Sun photometer AOT for a given effective LIDAR ratio (Young, 1995; Chazette, 2003). Considering the overall dataset, we find an average effective LIDAR ratio of $49 \mathrm{sr}$ and an associated standard deviation of $21 \mathrm{sr}$. We have also estimated the impact of the missing first $145 \mathrm{~m}$ on the retrieved effective lidar ratio by considering a constant aerosol extinction below $145 \mathrm{~m}$ and equal to the one estimated at this altitude. We retrieve a maximum bias of $-5 \mathrm{sr}$ under this hypothesis.

Fig. 5 shows the time evolution of the retrieved effective LIDAR ratio. The error bars are estimated for each retrieval by considering a perturbation of \pm 0.02 on the input AOT. The estimated error also depends on the actual profile of extinction. It is between 2 and $14 \mathrm{sr}$ and is weaker during the convective period of the day, because of the vertical mixing which tends to homogenize the surface layer. The effective LIDAR ratio is higher during the morning than in the afternoon. Before 9:30 UTC, the mean effective LIDAR ratio (24 data) is $65( \pm 15)$ sr while after this time it is $33( \pm 14) \mathrm{sr}$. This decrease in the LIDAR ratio clearly indicates a shift from an urban/industrial aerosol type to a more marine type (Ackerman, 1998; Müller et al., 2007). This point is in agreement with the decrease in the PM2.5/PM10 ratio observed in Fig. 2 showing an advection of large particles to the site. In this paper, we focus on the convective boundary layer and the sea breeze system, so we have considered here a LIDAR ratio of $33 \mathrm{sr}$. The error in the LIDAR derived extinction profile is difficult to estimate because we use here a constant effective LIDAR ratio and not an actual profile. However considering an error of $\pm 14 \mathrm{sr}$ in the effective LIDAR ratio, we calculate an error of $\pm 30 \%$ on the extinction coefficient below $1 \mathrm{~km}$.

Fig. 6 illustrates this rapid change in the atmospheric stratification by displaying the mean and standard deviation aerosol extinction profiles at 11:30, 11:45, 12:00 and 12:15 on July 25 th. At sea breeze onset there is a sharp increase in the mean aerosol extinction coefficient and standard deviation in the first $300 \mathrm{~m}$. The extinction at $145 \mathrm{~m}$ doubles every $15 \mathrm{~min}$ and reaches $1.94 \mathrm{~km}^{-1}$ at $12: 00$. At 11:30, a second maximum is located at $1.3 \mathrm{~km}$ and a third one at $1.8 \mathrm{~km}$. Those maxima are associated with negative gradients in the 


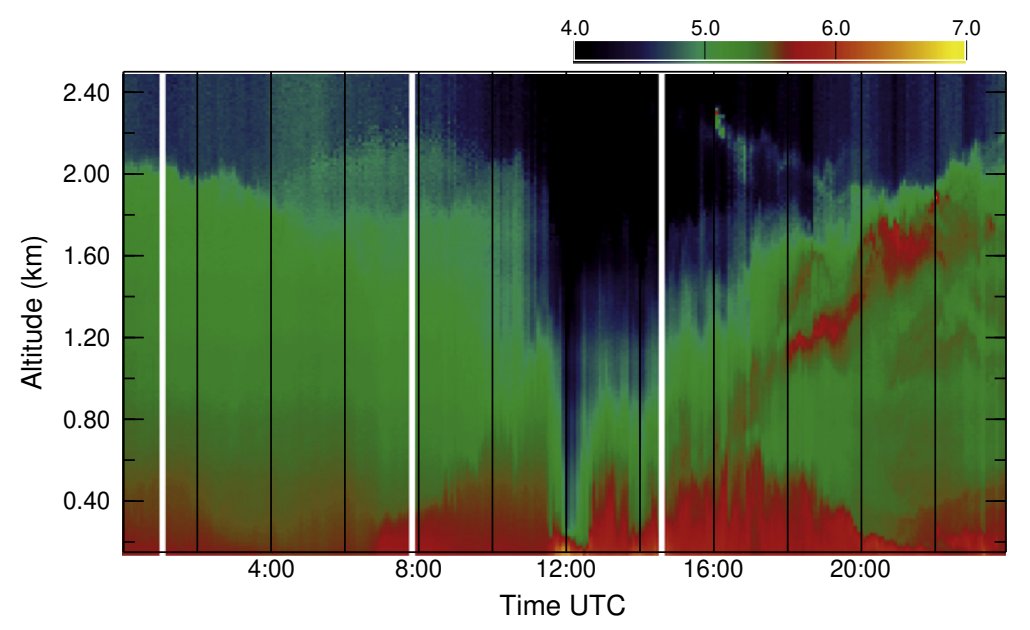

Fig. 3. 2-D plot of the logarithm of the range-corrected lidar signal on July 25, 2008.

extinction profile. A possible explanation for the second maximum is the advection of the continental atmospheric boundary layer $(\mathrm{ABL})$ over the site. The continental $\mathrm{ABL}$ is still convective until 12:30 and we observe an increase in the altitude of the secondary maximum in the standard deviation profile. In Fig. 6 it is located at $1.48 \mathrm{~km}$ at 12:15 UTC. The upper maximum corresponds to the residual layer. The residual layer is clearly observed in the afternoon and its altitude stays between 1.7 and $1.8 \mathrm{~km}$ (see also Fig. 3). At 12:00, the maximum of the standard deviation extinction profile is located at $200 \mathrm{~m}$. Above $300 \mathrm{~m}$ the standard deviation remains at the same level as before the start of the sea breeze.

To better highlight the impact of the frontal passage on the lidar-derived extinction coefficient, we have extracted the time series of 15-min average LIDAR derived aerosol extinction coefficient at the lowest detectable range, located at $145 \mathrm{~m}$ amsl. As shown in Fig. 7, there is a clear increase in the LIDAR derived extinction coefficient at $145 \mathrm{~m}$ during the sea breeze. This increase is simultaneous with the increase in

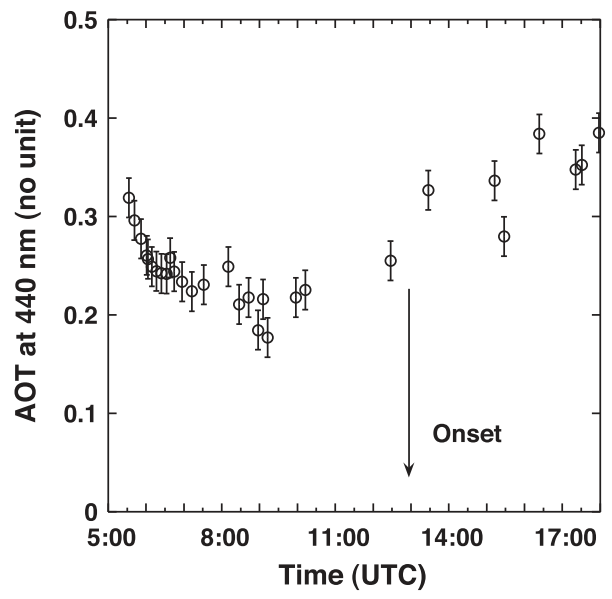

Fig. 4. Daily variation of AOT at $440 \mathrm{~nm}$ measured by Sun photometer on July 24, 2008. the PM10 (also plotted on Fig. 7) during the front overpass. Both quantities are correlated during this short time period, however the sharp increase in the extinction coefficient may not be totally explained by the change in aerosol concentration due to advection of sea-salt particles. Indeed, the change in relative humidity can affect the aerosol optical properties because the aerosol extinction cross section increases as a function of the relative humidity (Hänel, 1976). At the surface, the relative humidity changes between $50 \%$ and $70 \%$ during sea breeze. For those values, the change in extinction due to a change in refractive index and size is rather insensitive (Randriamiarisoa et al., 2006) However, at the top of the mixed layer, relative humidity can be close to saturation leading to a large increase in the aerosol extinction coefficient (Dupont et al., 1994). Without the actual profile of relative humidity, it is not possible to conclude on the relative importance of this parameter in the aerosol extinction increase compared to the advection of large particles. After $12: 30$, there is a clear divergence between the extinction coefficient and PM10 which may indicate that the landward flow of the sea breeze is below $145 \mathrm{~m}$.

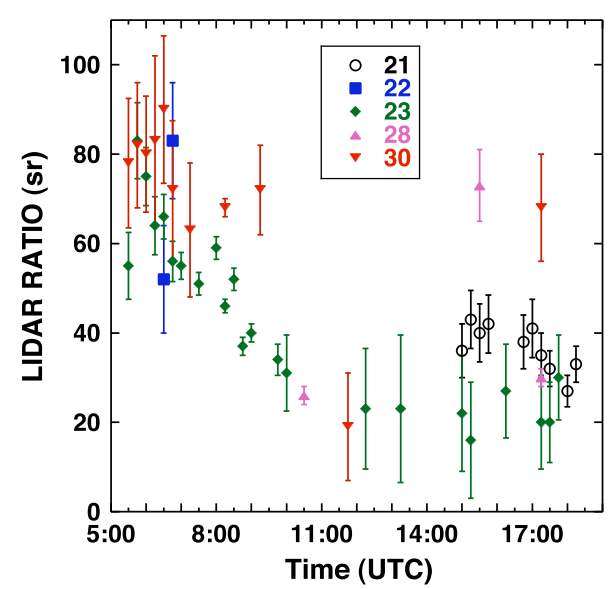

Fig. 5. Diurnal cycle of the effective LIDAR ratio retrieved on July 21, 22, 24, 28 and 30, 2008 using Sun photometer AOT. 


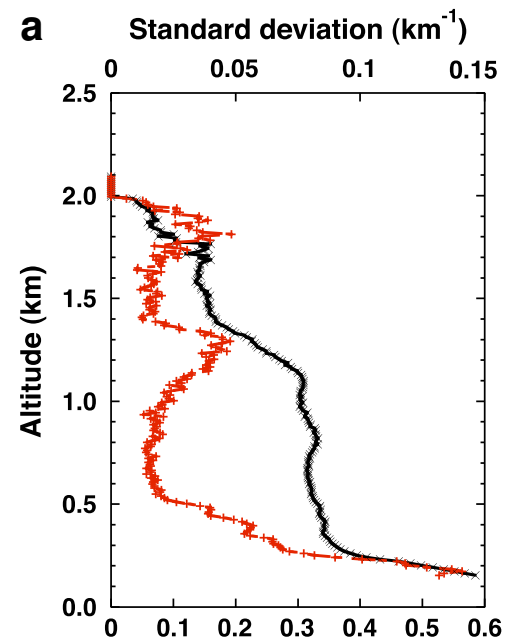

b Standard deviation $\left(\mathrm{km}^{-1}\right)$
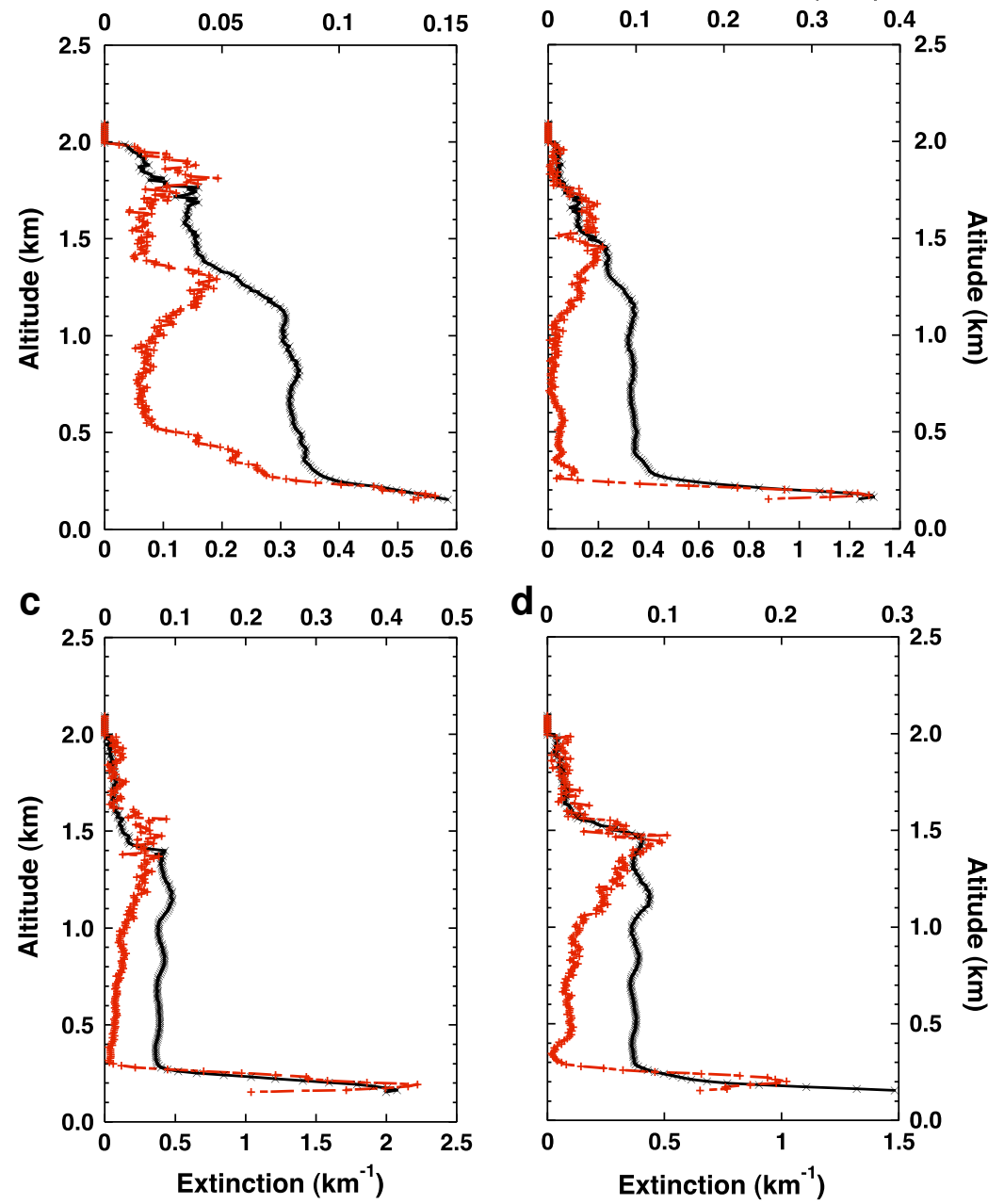

Fig. 6. 15-min average (black solid line) and standard deviation (red solid line) of aerosol extinction coefficient profiles at (a) 11:30, (b) 11:45, (c) 12:00 and (d) 12:15 UTC on July 25,2008 .

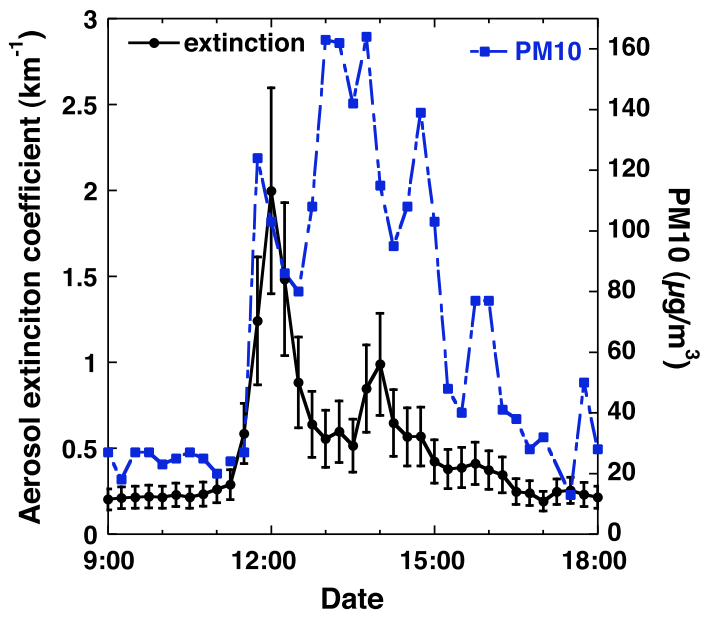

Fig. 7. Diurnal cycle in the LIDAR derived extinction at $145 \mathrm{~m}$ amsl and PM10 on July $25,2008$.

\section{Relationship between mixing height and PM2.5}

We present in Fig. 8 the altitude of the maximum in the standard deviation aerosol extinction profile observed on July 25 , 2008. In the early morning at night, the nocturnal boundary layer is not detected in the standard deviation profile. The Sun rises at 4:15 UTC. About 3 h later, the mixing layer height can be clearly identified in the standard deviation profile and is located at an altitude of $320 \mathrm{~m}$ amsl at 07:00 UTC. Due to solar heating, shallow convection develops (Stull, 1988) and the CBL top height increases. At 10:00, the CBL top is located at $800 \mathrm{~m}$. The CBL top grows until 11:15 UTC to $1300 \mathrm{~m}$ before the sea breeze starts. At this time the extinction coefficient is near constant in the CBL and close to $0.3 \mathrm{~km}^{-1}$. As the sea breeze front arrives, the absolute maximum in the standard deviation profile is located at the TIBL top. The mixing height drops from $1300 \mathrm{~m}$ to $174 \mathrm{~m}$ amsl in $15 \mathrm{~min}$. Until 12:30, the TIBL top can be monitored and is located between $174 \mathrm{~m}$ and $200 \mathrm{~m}$. After this time, the TIBL height cannot be detected because it 


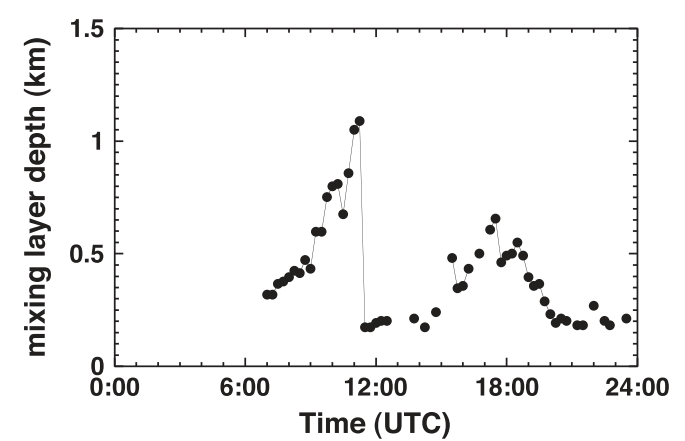

Fig. 8. Altitude of the LIDAR-retrieved mixing layer height on July 25, 2008.

was below $145 \mathrm{~m}$. In conjunction with this secondary decrease in the TIBL height, we also observe an increase in the PM10 concentration from 90 to $164 \mu \mathrm{g} / \mathrm{m}^{3}$ (Fig. 2). After $16: 00$, there is not much evidence of the presence of the sea breeze. After 18:00 and until the sunset at 20:00 UTC, the mixing layer height decreases. This decrease is simultaneous with a slight increase in the PM2.5 concentration. The nocturnal layer is located at about $200 \mathrm{~m}$ at the beginning of the night.

When looking closely at Fig. 2, we can observe different main tendencies in quarter-hourly PM2.5. We first focus on PM2.5 to avoid sea-salt and therefore emphasise the effect of variation in depth of the mixing layer. There is clearly some similarities between Fig. 2 and Fig. 8. A slight increase is observed until 6:00 UTC, which is probably connected to morning emission by car traffic. Between 7:00 and 11:15, there is a clear decrease in PM2.5 which is associated to the development of the convective activity and the growth of the CBL. The CBL development is stopped at 11:30 and then PM2.5 increases until 14:15 due to the drastic reduction in the mixing layer depth. After 14:15, PM2.5 decreases quasi continuously until 18:00 simultaneously with an increase in the mixed layer depth which passes by a maximum at 18:45. After this time the MBL height decreases while the PM2.5 increases until 19:45.

According to the simplest box model, the mean concentration of a given tracer in the CBL is inversely proportional to the mixing height and the mean wind speed in the mixed layer (Rigby et al., 2006). Fig. 9 presents the relationship between the inverse of the LIDAR-derived mixed layer depth and PM2.5 on July 25, 2008 between 7:00 and 19:45. The correlation is excellent between both data sets $\left(R^{2}=0.89\right.$ for a total of 42 data), except during the sea breeze between 11:30 and 12:30 (red squares in Fig. 9). Such a lack in correlation might indicate a weak mixing of the aerosol within the forming TIBL. Indeed, we observe a gradient in the aerosol extinction coefficient above $145 \mathrm{~m}$. Fig. 10 presents the ratio between the LIDAR derived extinction coefficient at 145 and $153 \mathrm{~m}$ amsl. A ratio close to 1.0 indicates that the extinction is near constant and thus that the atmosphere is well mixed. As the sea breeze starts, the ratio goes below 1.0 until 14:15 UTC. After this time, the ratio tends to be close to 1.0, except at 14:30. In Fig. 9, all the measurement points correspond to a ratio above 0.99 . The same behavior is observed on July 27. On this day, the correlation coefficient is $R^{2}=0.79$ (total of 15 data). However for this day, the

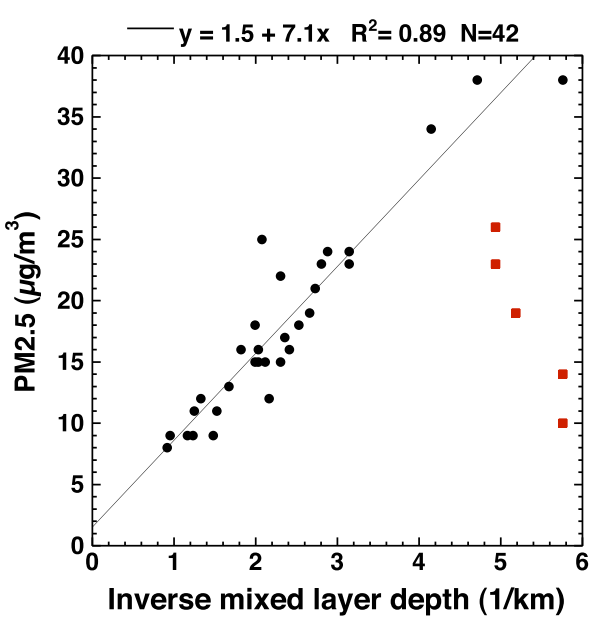

Fig. 9. PM2.5 as a function of the inverse of the mixing layer height. (black dots) before and after the breeze on July 25, (red square) during the breeze on July 25. The regression is made on the black dots.

situation is different mainly because of the early beginning of the sea breeze. Indeed the breeze starts at 9:40 UTC, $2 \mathrm{~h}$ earlier than on July 25 . At this time the CBL top is only at $500 \mathrm{~m}$.

\section{Conclusion}

Sea breezes are well known local scale meteorological phenomena that impact air quality in coastal areas. In this paper, we have analysed the variability in the LIDAR derived extinction coefficient during a sea breeze in 2008 in Dunkerque industrial and harbour area and its link with ground-level particle matter. As the convective activity starts in the morning, the PM2.5 ground-level concentration is well correlated to the inverse of the mixed layer depth. This indicates an effective dilution of pollutant in the growing boundary layer which is coherent with the weak gradient observed in the LIDAR derived extinction coefficient in the CBL. The sea breeze front is

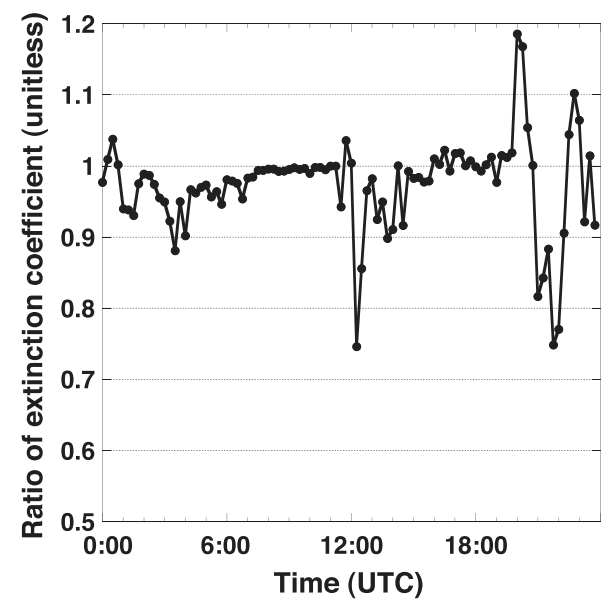

Fig. 10. Diurnal cycle in the ratio of LIDAR derived extinction at 145 and $153 \mathrm{~m}$ amsl. 
characterized by a sharp increase in the aerosol extinction coefficient below $200 \mathrm{~m}$ simultaneously with an increase in PM2.5 and PM10. The change in the PM2.5/PM10 ratio indicates the advection of large particles that could be attributed to sea-salt particles transported by the landward flow. We observe also a sharp vertical gradient in the extinction coefficient above the first accessible altitude located at $145 \mathrm{~m}$ amsl. Consequently, the LIDAR derived extinction at $145 \mathrm{~m}$ is not correlated to the PM10 or PM2.5 during the sea breeze. At the sea breeze set up, the maximum in the 15-min standard deviation profile drops from $1300 \mathrm{~m}$ to $174 \mathrm{~m}$. However, we observe that the PM2.5 is not correlated to the inverse of the TIBL during the sea breeze. After $2 \mathrm{~h}$, the low level gradient vanishes and the PM2.5 and the inverse of the mixed layer height are again correlated until the late afternoon.

Sea breezes exert a complex control on atmospheric pollution which is still not perfectly understood. The recent development of commercial compact elastic backscattering LIDAR enables unattended continuous long-term monitoring of aerosol vertical distribution at a high frequency. Our study presents a simple case study where the features detected in the LIDAR derived extinction provide new information on the diurnal cycle of PM during a sea breeze day. A detailed analysis of turbulent flux in the boundary layer before, and during sea breeze would be required to further understand the change in PM concentrations as a function of LIDAR derived vertical stratification.

\section{Acknowledgements}

The authors thank the European Commission (EC) for financial support through MEST-CT-2005-020659. The LPCA and LOA participate in the Institut de Recherches en ENvironnement Industriel (IRENI) which is financed by the Region Nord-Pas-de-Calais, the Ministère de la Recherche and European funds (FEDER). The authors are grateful to C. Beaugard (ATMO Nord-Pas de Calais) for providing Particulate Matter data.

\section{References}

Abbs, D.J., Physick, W.L., 1992. Sea-breeze observations and modelling: a review. Aust. Meteorol. Mag. 41, 7-19.

Ackerman, J., 1998. The extinction-to-backscatter ratio of tropospheric aerosol: a numerical study. J. Atmos. Oceanic Tech. 15, 1043-1050.

Angström, A., 1964. The parameters of atmospherics turbidity. Tellus 16, 64-75.

Ansmann, A., Müller, D., 2005. Lidar and atmospheric aerosol particle. In: Weitkamp, C. (Ed.), LIDAR: range resolved optical remote sensing of the atmosphere. : Springer series in optical sciences, volume 102. Springer, Geessthacht, Germany, pp. 105-141.

Augustin, P., Delbarre, H., Lohou, F., Campistron, B., Puygrenier, V., Cachier, H., Lombardo, T., 2006. Investigation of local meteorological events and their relationship with ozone and aerosols during an ESCOMPTE photochemical episode. Ann. Geophys. 24, 2809-2822.

Chazette, P., 2003. The monsoon aerosol extinction properties at Goa during INDOEX as measured with lidar. J. Geophys. Res. 107.

Chen, W.N., Oke, T.R., 1994. Mixed-layer heat advection and entrainment during the sea breeze. Boundary-Lay. Meteorol. 68, 139-158.

Cros, B., Durand, P., Cachier, H., Drobinski, P., Fréjafon, E., Kottmejer, E., Perros, C., Peuch, V.H., Ponche, J.L., Robin, D., Saïd, F., Toupance, G., Wortham, H., 2004. The ESCOMPTE program: an overview. Atmos. Res. 69, 241-279.

Damato, F., Planchon, O., Dubreuil, V., 2003. A remote sensing study of the inland penetration of sea breeze fronts from the English channel. Weather 58, 219-226.
Delbarre, H., Augustin, P., Saïd, F., Campistron, B., Bénech, B., Lohou, F., Puygrenier, V., Moppert, C., Cousin, F., Fréville, P., Fréjafon, E., 2005. Ground-based remote sensing observation of the complex behaviour of the Marseille boundary layer during ESCOMPTE. Atmos. Res. 74, 403-433.

Drobinski, P., Saïd, F., Ancellet, G., Arteta, J., Augustin, P., et al., 2007. Regional transport and dilution during high-pollution episodes in southern France: summary of findings from the field experiment to constrain models of atmospheric pollution and emission transport (ESCOMPTE). J. Geophys. Res. 112.

Dupont, E., Pelon, J., Flamant, C., 1994. Study of the moist convective boundary-layer structure by backscattering lidar. Boundary-Lay. Meteorol. 69, 1-25.

Estellés, V., Utrillas, M., Matinez-Lozano, J., et al., 2006. Intercomparison of spectroradiometers and Sun photometers for the determination of the aerosol optical depth during the VELETA-2002 field campaign. J. Geophys. Res. 111.

Fernald, F., 1984. Analysis of atmospheric lidar observations: some comments. Appl. Opt. 23, 652-653.

Georgieva, E., Canepa, E., Builtjes, P., 2007. Harbours and air quality. Atmos. Environ. 41, 6319-6321.

Hänel, G., 1976. The properties of atmospheric aerosol particles as functions of the relative humidity at thermodynamic equilibrium with surrounding moist air. Adv. Geophys. 19, 73-188.

Holben, B., Tanré, D., Smirnov, A., Eck, T., Slutsker, I., Abuhassan, N., Newcomb, W., Schafer, J., Chatenet, B., Lavenu, F., Kaufman, Y., Vande Castle, J., Setzer, A., Markham, B., Clark, D., Frouin, R., Halthore, R., Karneli, A., O'Neill, N., Pietras, C., Pinker, R., Voss, K., Zibordi, G., 2001. An emerging ground-based aerosol climatology: aerosol optical depth from AERONET. J. Geophys. Res. 106, 12,067-12,097.

Hooper, W., Eloranta, E., 1986. Lidar measurements of wind in the planetary boundary layer: the method, accuracy and results from joint measurements with radiosonde and kytoon. J. Climate Appl. Meteorol. 25, 990-1001.

Kitada, T., 1987. Turbulence structure of sea breeze front and its implication in air pollution transport-application of k-e turbulence model. Boundary Lay. Meteorol. 41, 217-239.

Klett, J., 1981. Stable analytical inversion solution for processing lidar return signal. Appl. Opt. 20, 211-220.

Kolev, I., Parvanov, O., Kaprielov, B., Donev, E., Ivanov, D., 1998. Lidar observations of sea-breeze and land-breeze aerosol structure on the Black Sea. J. Appl. Meteorol. 37, 982-995.

Kölsch, H., Rairoux, P., Wolf, J., Wöste, L., 1992. Comparative study of nitric oxide immission in the cities of Lyon. Geneva and Stuttgart using a mobile differential absorption lidar system. Appl. Phys. B 54, 89-94.

Léon, J.F., Derimian, Y., Chiapello, I., Tanré, D., Podvin, T., Chatenet, B., Diallo, A., Deroo, C., 2009. Aerosol vertical distribution and optical properties over M'Bour from 2006 to 2008. Atmos. Chem. Phys. 9, 9249-9261.

Levitin, J., Kambezidis, H., 1997. Numerical modelling of the thermal internal boundary-layer evolution using Athens field experimental data. Boundary Lay. Meteorol. 84, 207-217.

Lolli, S., Welton, E., Sauvage, L., 2008. EZ LIDAR measurement results in the frame of Indian Monsoon TIGER-Z NASA campaign. SPIE, Cardiff, U.K, p. 71110I.

Melas, D., Ziomas, I., Zerefos, C., 1995. Boundary layer dynamics in an urban coastal environment under sea breeze conditions. Atmos. Environ. 29, 3605-3617.

Melas, D., Ziomas, I., Klemm, O., Zerefos, C., 1998. Anatomy of the sea-breeze circulation in Athens area under weak large-scale ambiant winds. Atmos. Environ. 32, 2223-2237.

Menut, L., Flamant, C., Pelon, J., Flamant, P., 1999. Urban boundary-layer height determination from lidar measurements over the Paris area. Appl. Opt. 38, 945-954.

Mestayer, P., Durand, P., Augustin, P., et al., 2005. The urban boundary layer field experiment over Marseille UBL/CLU-ESCOMPTE: experimental setup and first results. Boundary Lay. Meteorol. 114, 315-365.

Miller, S., Keim, B., Talbot, R., Mao, H., 2003. Sea breeze: structure, forecasting, and impacts. Rev. Geophys. 41, 1011.

Müller, D., Ansmann, A., Mattis, I., Tesche, M., Wandingen, U., Althausen, D., Pisani, G., 2007. Aerosol-type dependent lidar ratios observed with Raman lidar. J. Geophys. Res. 112. doi:10.1029/2006JD008292.

Murayama, T., Okamoto, H., Kaneyasu, N., Kamataki, H., Miura, K., 1999. Application of lidar depolarization measurement in the atmospheric boundary layer: effects of dust and sea-salt particles. J. Geophys. Res. 104, 31,781-31,792.

Nakane, H., Sasano, Y., 1986. Structure of a sea breeze front revealed by scanning lidar observation. J. Meteor. Soc. Japan 64, 787-792.

Oke, T., 1978. Boundary layer climate, second edition. Methuen, London, UK.

Patashnick, H., Rupprecht, E., 1991. Continuous PM10 measurements using the tapered element oscillating microbalance. J. Air Waste Manage. Assoc. 41, 1079-1083. 
Piironen, A., Eloranta, E., 1995. Convective boundary layer mean depths and cloud geometrical properties obtained from volume imaging lidar data. J Geophys. Res. 100, 25,569-25,576.

Randriamiarisoa, H., Chazette, P., Couvert, P., Sanak, J., Mégie, G., 2006. Relative humidity impact on aerosol parameters in a Paris suburban area. Atmos. Chem. Phys. 6, 1389-1407.

Rigby, M., Timmis, R., Toumi, R., 2006. Similarities of boundary layer ventilation and particulate matter roses. Atmos. Environ. 40, 5112-5124.

Rimetz-Planchon, J., Perdrix, E., Sobanska, S., Brémard, C., 2008. PM10 air quality variations in an urbanized and industrialized harbor. Atmos. Environ. 42, 7274-7283.

Russel, P.B., Swissler, T., McCormick, M., 1979. Methodology for error analysis and simulation of lidar aerosol measurements. Appl. Opt. 18, 3783-3797.

Sicard, M., Pérez, C., Rocadenbosch, F., Baldasano, J.M., Garcia-Vizcaino, D. 2006. Mixed-layer depth determination in the Barcelona coastal area from regular lidar measurements: methods, results and limitations. Boundary-Lay. Meteorol. 119, 135-157.
Simpson, J.E., 1994. Sea breeze and local wind. Cambridge Univ, Press, New York.

Steyn, D., Oke, T.R., 1982. The depth of the daytime mixed layer at two coastal sites: a model and its validation. Boundary-Lay. Meteorol. 24, 161-180.

Stull, R., 1988. An introduction to boundary layer meteorology. Kluwer Academic Publishers, Dordrecht.

Talbot, C., Augustin, P., Leroy, C., Willart, V., Delbarre, H., Khomenko, G., 2007. Impact of a sea breeze on the boundary-layer dynamics and the atmospheric stratification in a coastal area of the North Sea. BoundaryLay. Meteorology 125, 133-154.

Young, S., 1995. Analysis of lidar backscatter profiles in optically thin clouds. Appl. Opt. 34, 7019-7031.

Ziomas, I., 1998. The Mediterranean campaign of photochemical tracerstransport and chemical evolution (MEDCAPHOT-TRACE): an outline. Atmos. Environ. 32, 2045-2053. 